\title{
FXLMS 알고리듬을 이용한 사각밀폐공간의 능동소음제어 Active Noise Control of a Closed Rectangular Cavity Using FXLMS Algorithms
}

\author{
류 경 완*.홍 진 숙†. 신 창 주*. 정 의 봉** \\ Kyung Wan Ryu, Chinsuk Hong, Changjoo Shin and Weuibong Jeong \\ (2010년 12월 16일 접수 ; 2011년 11월 1일 심사완료)
}

\begin{abstract}
Key Words : Active Noise Control(능동소음제어), FXLMS(filtered-x least mean square), Closed Rectangular Cavity(사각밀폐공간)
\end{abstract}

\begin{abstract}
This paper investigates active noise control(ANC) of a rectangular cavity using single channel filtered-x least mean square(FXLMS) algorithms to globally reduce the interior noise. To obtain the global reduction of the interior noise, multichannel active control should be incorporated in general. We, however, examined firstly the optimal location of the secondary source that produces a global reduction of the interior noise field using single channel control. We then investigated the frequency characteristics of the reduction to yield the effective frequency band of the active control system. It follows that the secondary source should be located as close to the primary source as possible in order to obtain the global reduction.
\end{abstract}

\section{1. 서 론}

과학이 발달하고 기술이 발전함에 따라 생활 패 턴 또한 많은 변화가 있었다. 과거에는 주로 실외에 서 활동하는 시간이 많았으나 최근에는 실내에서 활동하는 시간이 많아진 것이다. 이에 따라 실내소 음 문제가 발생하게 되었고 이를 줄이고자하는 노 력은 꾸준히 지속되어 왔다(1). 이러한 실내소음의 원인으로는 여러 가지가 있지만 편의를 위해 실내 에서 사용하는 각종 가전기기들과 차량내부의 에어 컨 등은 실내소음의 주된 요인이 되고 있다. 이러한 소음을 줄이기 위하여 가전기기 자체의 음압레벨을 줄이고자 하는 노력이 지속되어 $500 \mathrm{~Hz}$ 이상의 고

† 교신저자; 정회원, 울산과학대학 디지털기계학부

E-mail : cshong@uc.ac.kr

Tel : (052) 279-3134, Fax : (052) 279-3137

* 정회원, 부산대학교 대학원 기계공학부

** 정회원, 부산대학교 기계공학부
주파에 대한 소음은 크게 개선되었으나 $500 \mathrm{~Hz}$ 미 만의 저주파 대역의 소음에 대해서는 구조물 크기 의 한계와 주파수 특성으로 인해 그 감소 정도가 미미한 편이다(2). 하지만 능동소음제어를 이용할 경 우 공간의 제약 없이 효과적으로 저주파 소음을 줄 일 수 있다 ${ }^{(2)}$.

일반적으로 다양한 소음원이 존재하는 실내소음 을 줄이기 위해서는 여러 개의 참조신호와 여러 개 의 제어신호를 이용하는 $\mathrm{MIMO}$ (multi input/multi output) 제어기를 이용하여야 하지만 제어신호의 위 치가 최적의 위치에 놓일 경우 단 하나의 제어신호 만으로도 밀폐공간내의 평균 에너지를 줄이는 것이 가능하다 ${ }^{(3)}$. 그리고 차선의 위치에 또 다른 제어스 피커가 놓이는 경우 임의의 위치에 제어스피커를 배치하는 것 보다 더욱 높은 성능을 나타낸다 ${ }^{(3)}$.

이 연구에서는 여러 개의 참조신호를 이용 가능 하다고 가정하여 이론적인 경우인 단일 소음원만이 존재하는 경우 제어스피커의 위치에 따른 제어 성 
능과 제어스피커와 소음원의 거리에 따른 제어 성 능을 알아보고 좀 더 실제에 가깝게 접근하여 여러 개의 소음원이 존재하는 경우 제어스피커의 위치와 개수에 따른 제어 성능을 알아보았다. 또한 제어스 피커의 개수에 따른 제어 성능을 고찰함으로써 실 제 권장하는 스피커의 개수가 존재함을 보였다.

\section{2. 수학적 이론}

\section{1 제어기 설계}

Fig. 1에 간단한 1점 음압 최소화 앞섬 보상 제 어기(feedforward control)의 구조를 나타내었다. Fig. 1에서 볼 수 있듯이 소음원(noise source)으로 부터 전파되는 신호를 참조 마이크로폰을 통해 참 조신호(reference signal) $x(n)$ 으로 $\mathrm{A} / \mathrm{D}$ 변환되어 측정되고 그 신호가 제어기(controller) $H(z)$ 로 입 력되어 일련의 신호처리 과정을 거친다. 다음 제어 기로부터 계산된 제어신호(control signal) $u(n)$ 이 출력 되고 제어스피커를 통해 디지털(digital) 신호 가 아날로그(analogue) 신호로 변환되어 물리적 시 스템에 출력된다. 또한 소음원으로 부터 오차 마이 크로폰까지 전파되는 음향학적인 신호를 $d(n)$ 이라 하면, 제어신호 $u(n)$ 이 오차 마이크로폰까지 전파 되는 동안 $-d(n)$ 이 되면 오차신호(error signal) $e(n)$ 은 0 이 되어 이론적으로 $e(n)$ 의 음압은 0 이 된다. 이때 소음원으로 부터 $e(n)$ 까지의 경로 즉, $d(n)$ 이 생성되는 경로를 1차 경로(primary path)라 고 하며 제어신호 $u(n)$ 으로 부터 $e(n)$ 까지의 경 로를 일반적으로 2 차 경로(secondary path) 또는 에 러 경로(error path)라고 한다.

Fig. 1의 피드포워드 제어기를 블록선도(block diagram)로 나타내면 Fig. 2와 같다. 여기서 $P(z)$ 는 참조 마이크로폰으로부터 오차 마이크로폰까지의 1 차 경로이고 $C(z)$ 는 제어스피커로부터 오차 마이
크로폰까지의 2 차 경로이다. 그리고 $F(z)$ 는 제어스 피커로부터 참조 마이크로폰까지의 경로이다. 블록 선도에서도 알 수 있듯이 $F(z)$ 를 통해 음향학적 피 드백(acoustical feedback)이 발생하는 것을 알 수 있 다 ${ }^{(4)}$. 이와 같이 음향학적 피드백 현상은 참조신호 $x(n)$ 을 왜곡시킴으로 제어기에 $F(z)$ 가 고려되어야 제어기의 성능이 안정해지게 된다. 피드백과 노이즈 의 영향을 고려하면 블록선도를 Fig. 3과 같이 다시 표현할 수 있다. $F(z)$ 는 예측된 전달함수의 값이며 Fig. 3에서 알 수 있듯이 제어기에 $F(z)$ 가 고려되어 만약 $F^{\prime}(z)$ 가 $F(z)$ 와 동일하게 모델링 되었다면 피드포워드 제어기인 $W(z)$ 에는 $s(n)$ 이 아닌 $x(n)$ 이 입력으로 들어오고 음향학적 피드백 현상은 없다 고 봐도 무방하다는 것을 알 수 있다 ${ }^{(5)}$. 그러면 이제

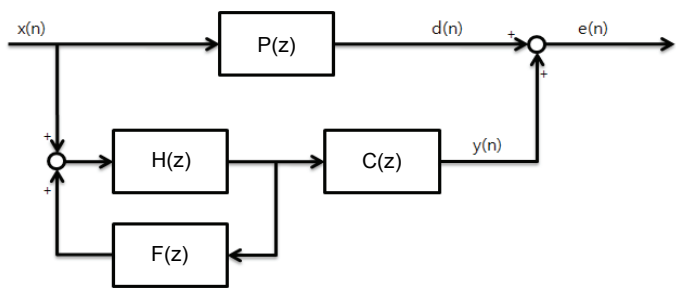

Fig. 2 Block diagram of a feedforward controller

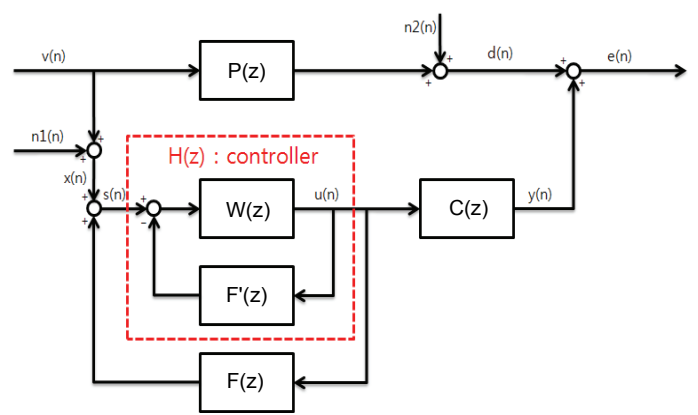

Fig. 3 Noise concerned block diagram of a feedforward controller

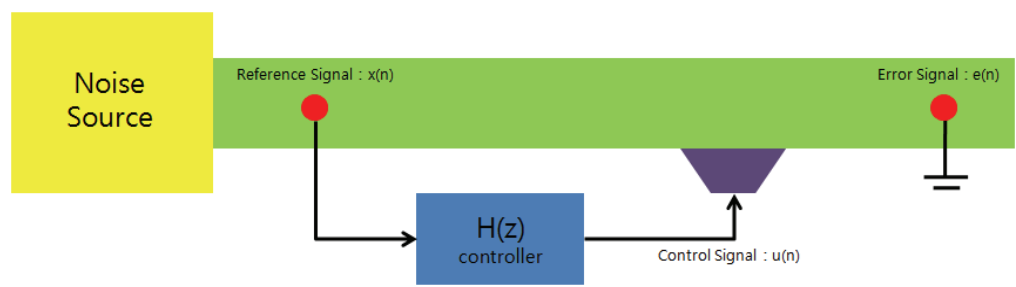

Fig. 1 Physical block diagram of a feedforward control system for the control of duct noise 
모델을 더욱 간단히 Fig. 4와 같이 표현 할 수 있다. 이제 $e(n)$ 을 최소로 하는 최적의 $W(z)$ 를 설계하면 $H(z)$ 를 설계할 수 있다. 그리고 $C(z)$ 와 $W(z)$ 가 선형(linear)이고 시불변(time invariant)인 시스템이면 Fig. 5와 같이 표현이 가능하다.

이제 블록선도는 완벽한 앞섬 보상 제어기 형태 가 되었다 ${ }^{(6)}$. 이에 대한 오차신호 $e(n)$ 은 다음과 같이 표현된다.

$$
e(n)=d(n)+y(n)
$$

오차의 파워를 최소화하는 필터 $W(j w)$ 는 유일 하며 최적의 $W(j w)$ 를 식 (2)와 같이 나타낼 수 있다 ${ }^{(2,7)}$.

$$
\therefore W_{o p t}(j w)=-\frac{S_{r d}(w)}{S_{r r}(w)}=-\frac{S_{x d}(w)}{C(w) S_{x x}(w)}
$$

다시 Fig. 3으로 돌아가서, 설계된 최적의 $W(j w)$ 를 적용하면 Fig. 6과 같이 최종적으로 음향학적 피 드백 현상이 고려된 제어기 $H(j w)$ 를 얻을 수 있으 며 식 (3)과 같이 계산된다.

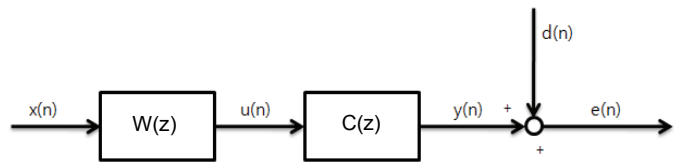

Fig. 4 Simplified block diagram of a feedforward controller

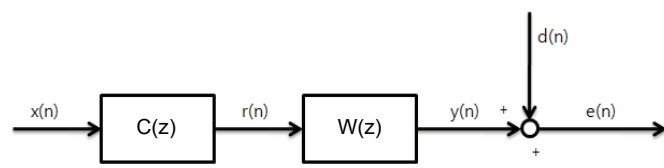

Fig. 5 Feedforward controller in which linear and time invariant system

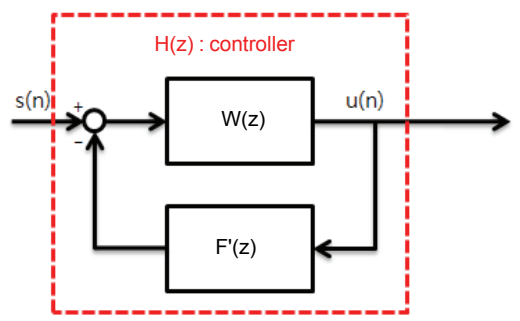

Fig. 6 Optimized feedforward controller

$$
\begin{aligned}
H_{o p t}(j w) & =\frac{W_{o p t}(j w)}{1+W_{o p t}(j w) F(j w)} \\
& =\frac{-S_{x d}(w)}{C(j w) S_{x x}(w)-F(j w) S_{x d}(w)}
\end{aligned}
$$

지금까지 살펴 본 하나의 참조신호를 이용하여 하나의 제어스피커를 구동하는 SISO FXLMS 제어 알고리듬은 MIMO FXLMS 제어 알고리듬으로 쉽 게 확장할 수 있다. 다채널 FXLMS 제어기는 다음 과 같이 나타낼 수 있다(6-8)

$$
\mathrm{H}_{\mathrm{opt}}=\left[\mathrm{I}+\mathrm{W}_{\mathrm{opt}} \mathrm{F}^{\prime}\right]^{-1} \mathrm{~W}_{\mathrm{opt}}
$$

여기서

$$
\mathrm{W}_{\mathrm{opt}}=-\left[\mathrm{C}^{\mathrm{H}} \mathrm{C}\right]^{-1} \mathrm{C}^{\mathrm{H}} \mathrm{S}_{\mathrm{xd}} \mathrm{S}_{\mathrm{xx}}^{-1} \text {. }
$$

\section{2 밀폐공간의 음압변화}

먼저 3 차원 파동 방정식은 식 (6)과 같다.

$$
\nabla^{2} p(x, y, z, t)=\frac{1}{c^{2}} \frac{\partial^{2} p(x, y, z, t)}{\partial t^{2}}
$$

식 (6)과 경계조건을 만족하기 위해서 사각 공간 내부의 음압은 식 (7)과 같이 나타난다.

$$
\begin{aligned}
& p(x, y, z, t)= \\
& \sum_{n} \sum_{m} \sum_{l} A_{l m n}(t) \cos \left(k_{x l} x\right) \cos \\
& \text { 기서, } \\
& k_{x l}=l \pi / L_{x}, l=0,1,2 \ldots \\
& k_{y m}=m \pi / L_{y}, m=0,1,2 \ldots \\
& k_{z n}=n \pi / L_{z}, n=0,1,2 \ldots
\end{aligned}
$$$$
\sum_{n} \sum_{m} \sum_{l} A_{l m n}(t) \cos \left(k_{x l} x\right) \cos \left(k_{y m} y\right) \cos \left(k_{z n} z\right)
$$

여기서,

여기서 $L_{x}, L_{y}, L_{z}$ 는 각각 $\mathrm{x}, \mathrm{y}, \mathrm{z}$ 방향의 길이이 며 $A_{l m n}$ 은 모드형상이다. 식 (7)로 부터 사각 공간 의 공진주파수는 식 (9)와 같이 나타낼 수 있다.

$$
\omega_{l m n}=c \sqrt{\left(l \pi / L_{x}\right)^{2}+\left(m \pi / L_{y}\right)^{2}+\left(n \pi / L_{z}\right)^{2}}
$$

또한 내부의 소음원에 의한 음압 변화는 식 (10)과 같이 나타낼 수 있으며 여기서 $\xi$ 는 사각 공간 내부 의 감쇠계수이며 $\rho_{0}$ 와 $c_{0}$ 는 각각 공기의 밀도와 공 
기중 소리의 전파속도이다. 그리고 $V=L_{x} \times L_{y} \times L_{z}$ 로써 사각공간의 부피를 의미하고 $q_{p}$ 와 $q_{s}$ 는 각각 소음원과 제어스피커의 유량이다.

$$
\begin{aligned}
& \stackrel{\ddot{A_{l m n}}}{(}(t)+2 \xi \omega_{l m n} \dot{A_{l m n}}(t)+\omega_{l m n}^{2} A_{l m n}(t) \\
& =\frac{\rho_{0} c_{0}^{2}}{V}\left[\sum_{h=1}^{H} \dot{q_{p h}} \psi_{l m n}\left(r_{q_{p h}}\right)+\sum_{g=1}^{G} \dot{q_{s h}} \psi_{l m n}\left(r_{q_{s h}}\right)\right]
\end{aligned}
$$

식 (10)에서 $\dot{q_{p h}}=0, \dot{q_{s h}}=1$ 일 경우에 대하여 구한 $A_{l m n}(t)$ 를 식 (7)에 대입 후 에러센서에서의 음향 응답이 $C$ 이고 참조센서에서의 음향 응답이 $F$ 가 된다. 이들 두 주파수 응답을 이용하여 제어기를 구 현할 수 있다. 구현된 제어기의 성능은 식 (11)와 같이 음향포텐셜에너지를 정의하여 제어 전후의 사 각박스 내부 에너지를 비교하여 평가할 것이다.

$$
E_{p}(\omega)=\frac{1}{4 \rho_{0} c_{0}^{2}} \int_{V}|p(x, y, z ; \omega)|^{2} d V
$$

\section{3. 시뮬레이션 결과}

Fig. 7은 시뮬레이션에 사용된 사각밀폐공간의 형 상이다. 그림에 보이는 사각 공간의 치수는 일반 승 용차의 부피를 참조하여 가로, 세로, 높이를 각각 $2.63 \mathrm{~m}, 1.46 \mathrm{~m}, 1.27 \mathrm{~m}$ 로 정하였으며 밀폐공간 내 의 음향매질은 공기로 채워져 있다. 음향매질의 물 성치는 밀도 $\rho_{a}=1.34 \mathrm{~kg} / \mathrm{m}^{3}$ 이고 음속 $c=340 \mathrm{~m} / \mathrm{s}$ 이 다. 밀페공간의 벽면은 음향학적으로 강체벽면(rigid wall)으로 가정하였다.

3.1절에서는 소음이 SPK.1의 위치에서만 발생하는 것으로 가정하였고 3.2 절에서는 더 많은 위치에 소음 원이 있다고 가정하였다. 또한 오차신호인 MIC.는

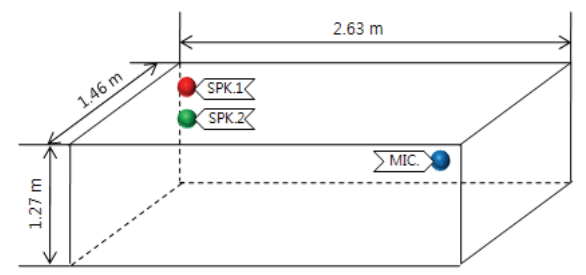

Fig. 7 Schematic representation of active noise control of a cavity
모든 노드에 있다고 가정하였다. 제어스피커는 임의 의 위치에 개수를 늘리거나 위치를 옮겨가며 시뮬 레이션 하였다.

\section{1 단일 소음원에 대한 제어 성능}

제어스피커와 소음원과의 관계를 알아보기 위하 여 Fig. 8과 같이 단 하나의 소음원만이 밀폐공간 내부에 존재 한다고 가정하였다. 그리고 단일 소음 원에 의한 내부에너지와 제어스피커의 거리와 위치 에 따른 제어 성능을 비교하였다.

(1) 소음원과 제어스피커의 거리에 따른 제어 성능 Fig. 8에서 보이는 바와 같이 소음원(primary source)과 제어스피커(secondary source)와의 거리 $r_{s}$ 를 변화시켜가며 제어 성능을 알아보았다. Fig. 9 에서 실선은 제어전의 음압 에너지를 나타내고 점 선은 제어스피커가 소음원과 $0.127 \mathrm{~m}$ 떨어진 경우, 파선은 소음원과 $0.327 \mathrm{~m}$ 떨어진 경우의 음압 에너 지를 나타낸다. 소음원의 위치좌표와 제어스피커의 위치를 Table 1에 나타내었다. Fig. 9에서 보이는 바 와 같이 제어스피커와 소음원의 거리가 가까운 경 우 제어 성능이 더욱 우수한 것을 알 수 있으며 이 론적으로 소음원의 위치에 제어스피커가 존재할 경 우 음압은 0 이 됨을 알 수 있다. 이는 소음원이 오 직 하나이기 때문에 가능한 결과이다.

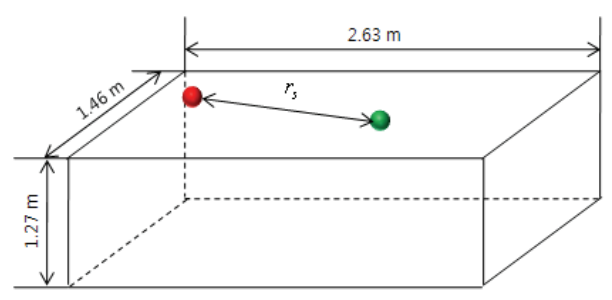

Fig. 8 Schematic representation of active noise control of a cavity $\left(r_{s}\right.$ : distance between the primary and secondary sources)

Table 1 Coordinates of the primary source and the secondary sources for $r=0.127$ and $r=0.327$

\begin{tabular}{c|c|c|c|c}
\hline \hline \multirow{2}{*}{\multicolumn{2}{c|}{ Sources }} & \multicolumn{3}{c}{ Coordinates $(\mathrm{m})$} \\
\cline { 3 - 5 } \multicolumn{2}{c|}{} & $\mathrm{x}$ & $\mathrm{y}$ & $\mathrm{z}$ \\
\hline \multicolumn{2}{c}{ Primary source } & 0.146 & 0.127 & 0.263 \\
\hline \multirow{2}{*}{$\begin{array}{c}\text { Secondary } \\
\text { source }\end{array}$} & $r=0.127$ & 0.146 & 0.254 & 0.263 \\
\cline { 2 - 5 } & $r=0.327$ & 0.292 & 0.254 & 0.526
\end{tabular}


(2) 제어스피커의 위치에 따른 제어 성능

제어스피커의 위치는 제어 성능에 큰 영향을 미치 는 인자이다. 이를 확인하기 위해 제어스피커의 위치 를 밀폐공간의 중심과 구석에 두어 각각을 제어효과 를 살펴보았다. 구석의 경우는 대부분의 모드와 잘 연성되는 위치이고 중심의 경우는 많은 모드에 대하 여 노달 면 또는 노달 라인이 된다. Table 2에는 소음 원과 각각의 제어스피커의 위치 좌표를 보이고 있다. Fig. 10에서 실선은 제어전의 사각밀폐공간의 음압에 너지 스펙트럼이며 점선은 제어스피커가 밀폐공간의 중심에 위치한 경우를 나타내었으며 파선은 제어스피 커가 소음원의 위치에서 반대로 떨어진 구석에 위치 한 경우의 음압에너지를 나타내었다. 제어스피커의 위치가 사각공간의 중심일 때 $200 \mathrm{~Hz}$ 이하의 대부분 의 모드에서 제어효과를 얻지 못하고 있다. 이는 시 뮬레이션에서는 사각공간의 내부가 비어있다고 가정 하였으므로 제어스피커가 공간의 중심에 위치하는 경 우 가장 많은 노달 라인을 지나게 된다. 반면, 제어스 피커가 사각공간의 구석에 위치하는 경우에는 4차 모 드를 제외하고는 대부분의 모드에서 제어 성능이 우 수함을 알 수 있다. 4차 모드의 경우, 제어스피커의 위치가 4차 모드의 모달 면에 해당하기 때문이다.

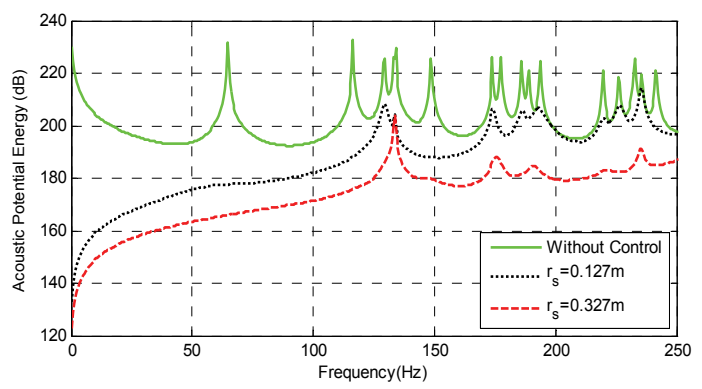

Fig. 9 Effects of the distance between primary and secondary sources on the acoustic potential energy

Table 2 Coordinates of the primary source and the secondary sources at the center and at the corner

\begin{tabular}{|c|c|c|c|c|}
\hline \multirow{2}{*}{\multicolumn{2}{|c|}{ Sources }} & \multicolumn{3}{|c|}{ Coordinates $(\mathrm{m})$} \\
\hline & & $\mathrm{x}$ & $\mathrm{y}$ & $\mathrm{z}$ \\
\hline \multicolumn{2}{|c|}{ Primary source } & 0.146 & 0.127 & 0.263 \\
\hline \multirow{2}{*}{$\begin{array}{c}\text { Secondary } \\
\text { source }\end{array}$} & Center & 0.730 & 0.635 & 1.315 \\
\hline & Corner & 1.314 & 1.143 & 0.263 \\
\hline
\end{tabular}

\section{2 다중 소음원에 대한 제어 성능}

앞서 3.1절에서는 단일 소음원에 대한 제어스피 커의 위치와 거리에 따른 제어 성능을 알아보았다. 하지만 실제의 실내공간에서는 단일 소음원만이 존 재한다는 것은 매우 특별한 경우에만 해당되며 주 로 여러 가지 복합적인 소음원에 의하여 소음이 발 생한다. 이 연구에서는 일반적인 차량을 참조하여 시뮬레이션 하였으므로 소음원 또한 실제 차량에서 발생할 수 있는 소음원 중 주요한 소음원만 가정하 여 고려하였다.

Fig. 11에서 알 수 있듯이 차량 내부에 엔진에 의 한 소음, 창문을 통한 소음 그리고 타이어를 통한 소음이 발생한다고 가정하였고 이들 소음원은 모노 폴(monopole)의 조합으로 가정하였으며, 위치좌표 는 Table 3 과 같다.

(1) 제어스피커의 위치에 따른 제어 성능

Fig. 12에 제어스피커의 위치에 따른 제어 결과를 나타내었다. Fig. 12의 실선은 제어하지 않은 경우 의 음압에너지를 나타내었고 점선은 제어스피커가 사각공간의 중심에 위치한 경우 그리고 파선은 제어

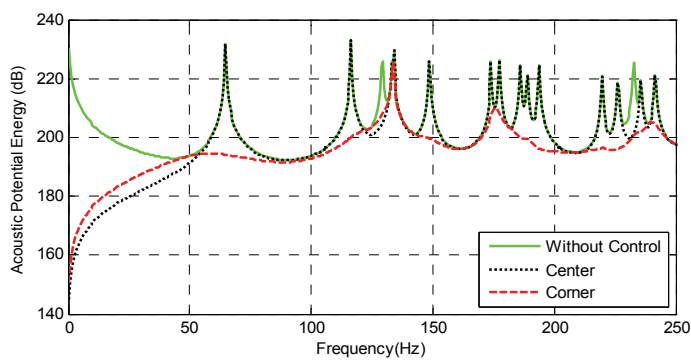

Fig. 10 Effects of the location of the secondary source on the acoustic potential energy of the cavity having a single primary source

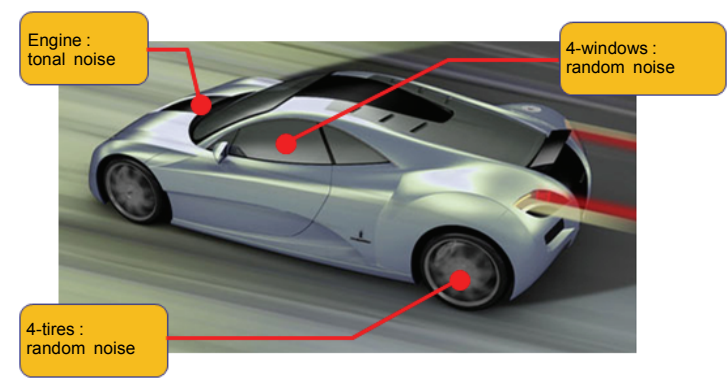

Fig. 11 Primary noise sources of a car 
Table 3 Coordinates of the primary noise sources

\begin{tabular}{c|c|c|c}
\hline \hline \multirow{2}{*}{$\begin{array}{c}\text { Type of primary } \\
\text { source }\end{array}$} & \multicolumn{3}{|c}{ Coordinates(m) } \\
\cline { 2 - 4 } & $\mathrm{x}$ & $\mathrm{y}$ & $\mathrm{z}$ \\
\hline \multirow{4}{*}{$\begin{array}{c}\text { Right window } \\
\text { of front seat }\end{array}$} & 0.1622 & 0.1411 & 0.5844 \\
\cline { 2 - 4 } & 0.1622 & 0.1411 & 1.1689 \\
\cline { 2 - 4 } & 0.4867 & 0.1411 & 0.5844 \\
\cline { 2 - 4 } & 0.4867 & 0.1411 & 1.1689 \\
\hline \multirow{4}{*}{$\begin{array}{c}\text { Left window } \\
\text { of front seat }\end{array}$} & 0.1622 & 1.27 & 0.5844 \\
\cline { 2 - 4 } & 0.1622 & 1.27 & 1.1689 \\
\cline { 2 - 4 } & 0.4867 & 1.27 & 0.5844 \\
\cline { 2 - 4 } & 0.4867 & 1.27 & 1.1689 \\
\hline \multirow{4}{*}{$\begin{array}{c}\text { Right window } \\
\text { of rear seat }\end{array}$} & 0.1622 & 0.1411 & 2.0456 \\
\cline { 2 - 4 } & 0.1622 & 0.1411 & 2.63 \\
\cline { 2 - 4 } & 0.4867 & 0.1411 & 2.0456 \\
\cline { 2 - 4 } & 0.4867 & 0.1411 & 2.63 \\
\hline \multirow{4}{*}{$\begin{array}{c}\text { Left window } \\
\text { of rear seat }\end{array}$} & 0.1622 & 1.27 & 2.0456 \\
\cline { 2 - 4 } & 0.1622 & 1.27 & 2.63 \\
\cline { 2 - 4 } & 0.4867 & 1.27 & 2.0456 \\
\cline { 2 - 4 } & 0.4867 & 1.27 & 2.63 \\
\hline \multirow{4}{*}{ Tire } & 1.46 & 0.1411 & 2.63 \\
\cline { 2 - 4 } & 1.46 & 1.27 & 2.63 \\
\cline { 2 - 4 } & 1.46 & 0.1411 & 2.63 \\
\hline \multirow{4}{*}{ Engine } & 1.46 & 1.27 & 2.63 \\
\hline & 0.9733 & 0.8467 & 0.2922 \\
\hline
\end{tabular}

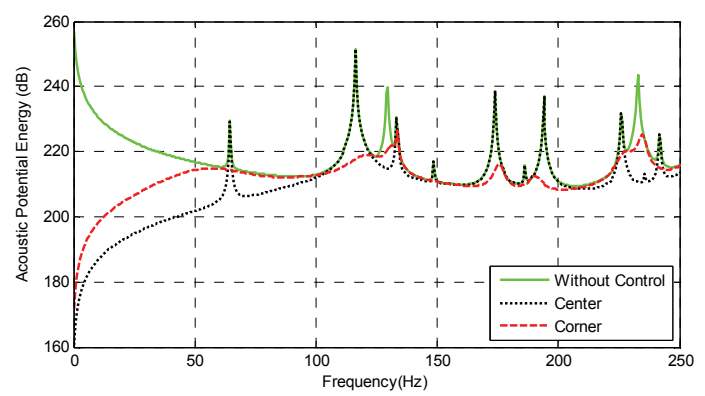

Fig. 12 Effects of the location of the secondary source on the acoustic potential energy of the cavity having multiple primary sources

스피커가 구석에 위치한 경우의 음압에너지 스펙트 럼이다. 제어스피커의 위치는 Table 2 에서 보이고 있으며 3.1 의 경우와 동일하다. 앞서 살펴본 3.1절 의 결과와 유사한 결과를 나타내고 있으며 소음원 이 여러 개인 경우에도 제어스피커의 위치는 매우 중요하다고 할 수 있다.

Fig. 13 에 제어전과 제어후의 에너지 비를 임의의 단면에 대하여 나타낸 것이다. 에너지 비는 식 (12) 와 같이 정의된다.

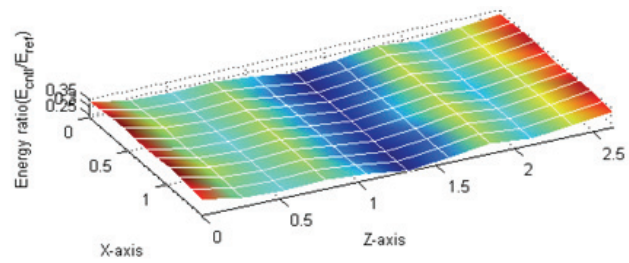

(a) Center

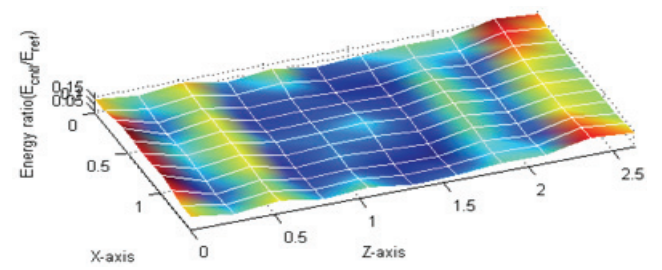

(b) Corner

Fig. 13 Energy ration over a surface in the cavity when the secondary control source is located at (a) center and (b) corner

$$
\text { Energy ratio }=\frac{\int\left|p_{c}(x, y, z)\right|^{2} d \omega}{\int\left|p_{p}(x, y, z)\right|^{2} d \omega}
$$

여기서 $p_{p}$ 는 제어 전 $(x, y, z)$ 공간상의 음압이며, $p_{c}$ 는 제어 후 $(x, y, z)$ 공간상의 음압이다. Fig. 13(a)는 Fig. 12의 제어스피커가 노달 라인에 위치 한 경우 즉, 공간의 중심에 위치한 경우의 에너지 비이고 Fig. 13(b)는 노달 라인을 피하여 스피커를 위치시킨 경우 즉 구석에 제어스피커가 위치한 경 우의 에너지 비이다. Fig. 13의 결과에서도 노달 라 인을 피하여 제어스피커가 위치한 경우 임의의 단 면에 대하여 더 넓은 영역의 소음감소가 나타남을 알 수 있었다.

(2) 스피커의 개수에 따른 제어 성능

제어스피커의 개수에 대한 성능 변화를 관찰하기 위해 식 (4)와 (5)에서 보이고 있는 다채널 FXLMS 제어 알고리듬을 사용하였다. Fig. 14에 스피커의 개수에 따른 제어 성능을 나타내었다. Fig. 14에서 실 선은 제어하지 않은 경우의 음압에너지 스펙트럼을 나타내었고 점선은 제어스피커가 4개인 경우의 음압 에너지 스펙트럼이다. 또한 파선은 제어스피커가 8개 인 경우의 음압에너지 스펙트럼이다. Fig. 14로부터 알 수 있듯이 제어스피커의 개수가 늘어남에 따라 


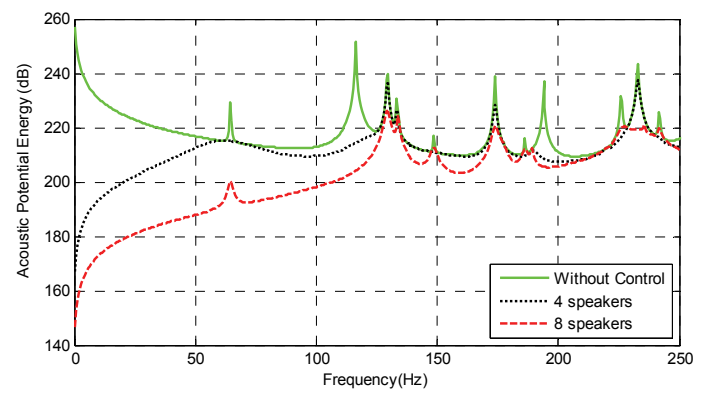

Fig. 14 Effects of the number of the secondary sources on the acoustic potential energy of the cavity having multiple primary sources

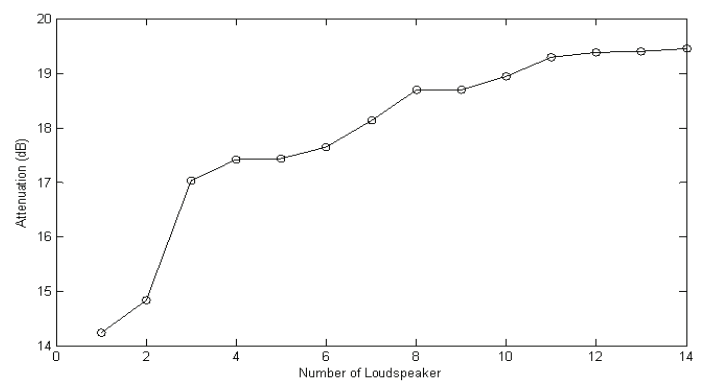

Fig. 15 Variation of the attenuation of the total acoustic potential energy with the number of the secondary sources

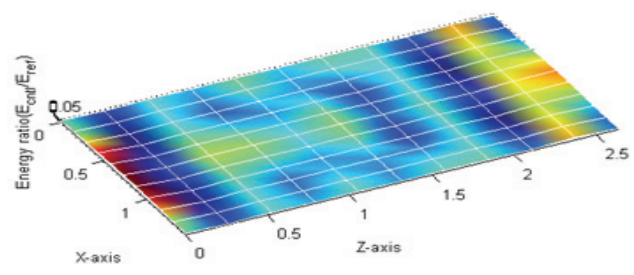

(a) With 4 secondary sources

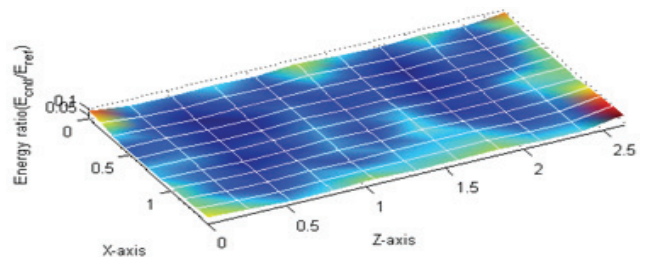

(b) With 8 secondary sources

Fig. 16 Energy ratio over a surface in the cavity when (a) 4 secondary sources and (b) 8 secondary sources are used

제어 성능 역시 좋아짐을 알 수 있다. 특히 저주파 영역의 소음이 크게 줄어드는 것을 알 수 있다. 하
지만 제어스피커의 개수에 따른 음압에너지 감소정 도를 나타낸 Fig. 15 를 보면 제어스피커의 개수와 제어 성능이 비례하지 않음을 알 수 있다. 이는 곧 가장 효율적인 제어스피커의 개수가 있음을 의미하 며 Fig. 15에 따르면 제어스피커가 8개 이상인 경우 에는 제어스피커 증가에 따른 소음 저감효과가 그 리 크지 않은 것을 알 수 있다.

Fig. 16에는 Fig. 13과 같이 식(21)에 의해 정의된 제어전후의 에너지비를 나타내었다. Fig. 16(a)에는 스피커가 4개인 경우를 나타내었고 Fig. 16(b)에는 스 피커가 8 개인 경우의 에너지 비를 나타내었다. 그림 에서 알 수 있듯이 4 개의 제어스피커를 이용한 경우 보다 8 개의 제어스피커를 이용하는 경우가 더 큰 영 역의 소음 감소를 보이는 것을 알 수 있다.

\section{4. 결 론}

이 연구는 실내에서 발생하는 소음을 줄일 수 있 는 방법에 관한 것이다. 공간 내부에 단일 소음원이 존재하는 경우와 여러 개의 소음원이 존재하는 경 우를 서로 비교하였으며 단일 소음원이 존재하는 경우 제어스피커가 소음원에 가까울수록 더 큰 제 어 효과를 나타냄을 확인하였고 제어스피커의 위치 가 제어 성능에 큰 영향을 끼침을 알 수 있었다. 그 로부터 노달 라인이 잘 나타나지 않는 지점에 제어 스피커를 위치시킬 경우 우수한 성능을 나타냄을 알 수 있었다. 또한 다중 소음원이 존재하는 경우 제어스피커의 개수가 늘어남에 따라 제어 성능 또 한 좋아짐을 확인하였으나 제어스피커의 개수에 따 라 제어 성능이 비례하지 않는다는 것을 알 수 있 었다. 이로부터 공간의 특성과 소음원의 개수에 따 라 적정한 개수의 제어스피커 개수의 선정이 가능 함을 보일 수 있었다.

\section{후 기}

이 연구는 교육과학기술부의 교육역량강화사업비 지원에 의해 수행됨.

\section{참 고 문 헌}

(1) NOVI Mich, 2008, Retrieved 21 July 2008, 
Eberspaecher Puts Speakers Into Car Mufflers, Find Articles Website: http://findarticles.com/p/articles/mi_m 0EIN/is_/ai_n27928872.

(2) Kuo, S. M. and Dennis R. M., 1996, Active Noise Control Systems: Algorithms and DSP Implementations, John Wiley \& Sons, Inc., New York.

(3) Sutton, T. J., 1992, The Active Control of Random Noise in Automative Interiors, A Thesis Submitted for the Degree of Doctor of Philosophy.

(4) Woo, J, H., Kim, I. S., Ih, J. G. and Kim, K. J., 1992, Active Noise Control of the Plane Wave Travelling in a Duct Using Filtered-x LMS Algorithm, Transactions of the Korean Society Noise and Vibration Engineering, Vol. 2, No. 2, pp. 107 116.

(5) Blazier, W. E. Jr., 1997, RC Mark II: A
Refined Procedure for Rating the Noise of Heating, Ventilating, and Air-conditioning(HVAC) Systems in Buildings, Noise Control Eng. J. Vol. 45, No. 6, pp. 243 150.

(6) Nelson, P. A. and Elliott, S. J., 1994, Active Control of Sound, Academic Press, A Harcourt Science and Technology Company, New York.

(7) Elliott, S. J., Stothers, I. M. and Nelson, P. A., 1987, A Multiple Error LMS Algorithm and Its Application to the Active Control of Sound and Vibration, IEEE Transactions on Acoustics, Speech, and Signal Processing, Vol. ASSP-35, No. 10, pp. $1423 \sim 1434$.

(8) Elliott, S. J., 2001, Signal Processing for Active Control, Academic Press, A Harcourt Science and Technology Company, New York. 